\title{
Estado actual de la transformación religiosa: libertad de religión-Estado, educación y laicismo en El Salvador"
}

\author{
Antonia Larissa Hernández Monterrosa*
}

Recepción: 10 de noviembre de 2018 • Aprobación: 5 de diciembre de 2018

\section{Resumen}

El propósito de este artículo es exponer el estado actual de la transformación religiosa: libertad de religión-Estado, educación y laicismo de El Salvador desde la Colonia hasta la actualidad, brindando un panorama de esta relación en la sociedad salvadoreña y cómo con el transcurso de los años llegaron a establecerse otras religiones en el país. Para la recopilación de la información, se consultó bibliografía relacionada con el tema. Como principal resultado, se encontró que en El Salvador existe la libertad de culto. Finalmente, se hace una reflexión sobre la importancia de la religión en la vida de las personas y por qué existe la necesidad de creer en un ser supremo que está al pendiente de las necesidades de su pueblo.

Palabras clave: religión, Estado, educación, laicismo.

* Artículo producto del proyecto de investigación "Estado actual de la transformación religiosa en América Latina y el Caribe", desarrollado en el Observatorio de la Diversidad Religiosa y de las Culturas en América Latina y el Caribe entre 2015 y 2016. Citar como: Hernández Monterrosa, A. L. (2019). Estado actual de la transformación religiosa: libertad en la relación religión-Estado, educación y laicismo en El Salvador. Albertus Magnus, X(2), 35-55. DoI: https://doi.org/10.153322/5005413.5212.

** Universidad Católica de El Salvador, El Salvador. Orcid: http://orcid.org/0000-00025187-9057. Correo electrónico: larissa.hernandez@catolica.edu.sv 


\title{
State of the art of religious transformation: Freedom of religion-State, education and secularism in El Salvador
}

\begin{abstract}
The purpose of this paper is to expose the state of art of religious transformation: Freedom of Religion-State, education and secularism of El Salvador from the Colony to the present, providing an overview of this relationship in Salvadoran society and how with the course from the year's other religions in the country were established. For the collection of information, bibliography related to the subject was consulted. As a main result, it was found that freedom of worship exists in El Salvador. Finally, a reflection is made on the importance of religion in the lives of people and because there is a need to believe in a supreme being who is aware of the needs of his people.
\end{abstract}

Keywords: religion, State, education, secularism

\section{Estado da arte da transformação religiosa: liberdade religiosa-Estado, educação e laicidade em El Salvador}

\section{Resumo}

O propósito de este escrito é exponente sobre o Estado do Arte da transformação religiosa: Libertad de religião-Estado, educação e lazer de El Salvador desde a Colonia até a atualidade, brindando um panorama desta relação na sociedade salvadoreña e como com o transcurso de los años chegaron a outras religiões estabelecidas em país. Para a recopilação de informação e consulta bibliografia relacionada ao tema. Como resultado principal, se encontró que em El Salvador existe a liberdade de culto. Finalmente, é uma reflexão sobre a importância da religião na vida das pessoas e porque existe a necessidade de criar um ser supremo que está pendurado nas necessidades de su pueblo.

Palavras-chave: religião, Estado, educação, laicidade. 


\section{Introducción}

La religión en América Latina ha suscitado transformaciones que han afectado los aspectos educativo, social y político a lo largo de su historia. Esta se considera un fuerte vínculo entre el hombre y Dios, ya que se está consciente que de un ser celestial está presente en la vida y que gracias a su bondad y misericordia se producen milagros.

Este estudio hace énfasis en el estado actual de la transformación religiosa: libertad de religión-Estado y educación, y laicismo de El Salvador desde la Colonia hasta la actualidad. Además, establece un panorama que permite visualizar cómo el país ha experimentado cambios en cuanto a la apertura a religiones a lo largo del tiempo, de modo que surgió la siguiente pregunta de investigación: ¿cómo ha sido el estado actual de la transformación religiosa: libertad de religiónEstado, educación y laicismo de El Salvador desde la Colonia hasta la actualidad? Para ello, se realizó una recopilación de información de la transformación de la religión de El Salvador, que se describió y analizó, para proporcionar una idea más amplia de este aspecto tan importante en la sociedad, que es la religión. La investigación básicamente fue de tipo documental-informativo, para lo que se consultaron fuentes primarias y secundarias: libros, revistas científicas, documentos oficiales e informes técnicos de instituciones públicas y privadas. El instrumento para procesar la información fue una ficha de revisión, a fin de tener una panorámica acerca de la información relevante de diversas fuentes confiables, considerando los indicadores y objetivos establecidos. El enfoque del análisis de la literatura consultada fue sobre la transformación de la religión en El Salvador, que se ubica desde la Conquista misma de los españoles al pueblo indígena hasta la época actual.

\section{Conceptualización de religión}

La religión es un concepto difícil de definir, principalmente debido a su diversidad de manifestaciones a través de las diferentes culturas. El fenómeno religioso como expresión de la consciencia resulta un hecho antiguo y su investigación ha sido de interés tanto para practicantes como para observadores, entre ellos, filósofos, ideólogos, historiadores, médicos, sociólogos, psicólogos y representantes de otras ciencias, lo mismo a partir de teorías generales y concepciones preponderantes en cada época, la perspectiva personal, la experiencia práctica y las vivencias de los que han decidido su indagación y explicación. 
En este sentido, la religión como forma de concepción del mundo aporta sentidos al hombre, aun cuando no sea la única fuente. Al analizar el término de religión, se tienen en cuenta tres niveles cuyo marco subjetivo se expresa como creencia, simbolismo, imaginario y convencimiento; además, se analiza el nivel de las interacciones sociales en las que se expresa en comportamientos, conductas, formas de llevar la vida, ritos y costumbres; también en el nivel institucional, donde se encuentran instituciones como iglesias, con un fuerte componente de poder (Möller, 2008). Desde este planteamiento, no hay duda de que la religión influye fuertemente en la vida de los seres humanos, porque en ella encuentran consuelo y orientación para los problemas existenciales que se tienen en un momento de la vida, es decir, que "la religión es uno de los mecanismos universales que permite acceder a las formas de integración y de cohesión de una sociedad" (Gispert, 2006, p. 123). Para ilustrar mejor este concepto, la religión es una forma de tener unificada a la sociedad, y lo que se busca es estar en paz y en armonía con el prójimo, lo que provoca que la sociedad funcione integralmente, por la misma convicción que al tratar bien a las personas se cumple con la invitación que Jesús hizo a los hombres y que conduce a las raíces del cristianismo. También se debe agregar que amar al prójimo es comprender que este no solo es humano, sino también lo universal, es decir, todo lo creado, la tierra, el agua, la selva, los animales, todo cuanto existe, y que compartimos en este planeta, llamado Tierra, por tanto, es a través de la religión que se tiene una comunión entre todos estos elementos mencionados. Anteriormente, los indígenas tenían esa comunión con la naturaleza, a su manera, claro está, y que al llegar los españoles los orientaron a vivir en comunión con lo que les rodeaba, pero a través de una sola religión. A continuación, se hace un breve recorrido por esta época en El Salvador.

\section{2. Época prehispánica y colonial en El Salvador}

En la época prehispánica, los antepasados indígenas tenían establecido su propio mundo politeísta, es decir, que "creían que cualquier fenómeno natural: el sol, la luna, la lluvia los animales eran dioses y realizaban ceremonias dedicadas a cada uno para mantener el ciclo vital de la existencia" (Ministerio de Educación, 2010, p. 11). Esto es, los indígenas tenían sus ritos para cada una de sus deidades, por ejemplo, el ritual más importante para ellos era el del dios Lol Cah, que era el que prevenía las sequías ofrendando el árbol sagrado al dios Chac (de la lluvia), por mencionar uno de los muchos que ellos realizaban. Entonces, a la llegada de los españoles, específicamente el 12 de octubre de 1492, estos rituales fueron 
eliminados e iniciaron la conquista de América y comenzaron a imponer el catolicismo en las comunidades indígenas durante la época colonial.

Transcurrido el tiempo en la historia de la Iglesia en El Salvador, según Delgado (2011), "la primera comunidad de creyentes comenzó a congregarse en la Villa de San Salvador. Esta comenzó a celebrar su fe en Cristo y dar testimonio de Él en tierra de pipiles, en Cuscatlán" (p. 23), lo que indica que los españoles ya habían dominado a los indígenas para que practicaran la adoración a un solo Dios e inducirlos al catolicismo, religión que los conquistadores profesaban.

En esta época colonial, los párrocos de las iglesias católicas, por encargo del rey de España, enseñaban doctrina religiosa a los indígenas. En efecto, fue durante la formación de la República, en 1832, que surgió el primer reglamento de enseñanza que indicaba: "En todos los pueblos del país que tengan municipalidad, deben tener escuela de primeras letras, con cien pesos de multa si no lo hicieran" (Aguilar, 1995, p. 14). Ante este mandato, había una cierta presión para que se implementara la educación en el país. Es de mencionar que, en un principio, la educación se enfocaba en enseñar la doctrina cristiano-católica. En El Salvador, en 1832, aún no estaba reglamentada la enseñanza de la doctrina católica, pero en 1861 sí fue contundente que se tenía que realizar esta actividad. González (2012) explica que a partir "del año 1824 hasta 1880, la educación moral de los futuros ciudadanos estuvo regida por los principios, valores y dogmas del catolicismo; y el Estado salvadoreño avaló ese tipo de educación, es decir, la formación de futuros ciudadanos católicos" (p. 12). Es decir, se buscó dar una formación enfocada en la religión para que los ciudadanos del país fueran personas de bien y practicantes de valores que fortalecen la convivencia social.

No obstante, a partir de 1873, esta situación empieza a cambiar. Durante el Gobierno del mariscal Santiago González se redacta un nuevo reglamento de educación en el que se promueve la educación integral y se daba un separación entre la religión y la educación, que da origen al modelo laico de educación que es el mayoritario en los centros educativos nacionales, incluso hasta hoy en día (Lorenzana, Mena, Regalado y Rodríguez, 2011). Una característica que todavía se mantiene en las instituciones educativas públicas es que en estas no se permite enseñar religión a los estudiantes, a diferencia de las privadas que, a este respecto, son autónomas, lo que quiere decir que, si tienen bases católicas o evangélicas, la enseñanza estará enfocada en esa religión. Además, en la Constitución de la República de El Salvador de 1983, se instaura la libertad de culto y se afirma que todas las personas son iguales ante la ley, y prohíbe la discriminación basada en la religión.

Continuando con la historia de la religión católica en El Salvador, durante la época colonial, la relación Iglesia-Estado se firmó a través del Patronato, lo que 
le otorgó al catolicismo el derecho de ser la única religión en los territorios bajo la influencia de la Corona española. En esta experiencia, la monarquía hispánica y la Santa Sede resultaron beneficiadas. El clero, las órdenes religiosas y la alta jerarquía cumplieron funciones propias del culto católico, pero además llevaron sobre sus hombros tareas propias del Estado español. Cabe mencionar que durante la Colonia se consolidó la identidad y la cultura cristiana a través de los sacramentos y la catequesis.

Para el historiador del derecho indiano, el Estado español en las Indias se fue configurando como un Estado misional. Fue su originalidad y lo que lo define como un Estado misional frente al Estado confesional, que por la misma época cobra forma en Europa. Bravo citado por Avendaño (2012), explica:

Se reconoce y protege una religión establecida como oficial católica, el Estado misional tiene como fin primordial procurar atraer a sus vasallos a la fe católica, es decir, promover el establecimiento de esa religión. Esa intrínseca relación política no se disolvió al momento de la declaración de la Independencia centroamericana, más bien hubo un incremento de tensión entre las antiguas provincias y el gobierno federal por la definición del Patronato. Tal asunto se resolvió con la llegada de Francisco Morazán a la presidencia de la República Federal, a raíz del cual, un decreto aclaró que el Patronato correspondía al gobierno federal y el vice patronato lo ejercía cada uno de los estados. (párr. 2)

De esta forma, el Patronato entre las antiguas provincias del Reino de Guatemala y un recuento de la legislación estatal brindó el respaldo a una corporación de antiguo régimen de la Iglesia católica; al parecer, en esa época, las fracciones políticas centroamericanas de diferentes signos brindaron su protección al culto católico, pero permitieron la presencia a otras agrupaciones religiosas en el ámbito privado para respetar la libertad de esta índole. De modo que, entre 1824 y 1880, El Salvador vivió una clase de "modernidad católica"; en la década de 1880, el Estado salvadoreño se empeñó por establecer la modernidad de corte laico y secular. González (2012) refiere que "la primera modernidad estaría caracterizada por la fuerte presencia de la religión católica en la esfera política, mientras que la segunda estaría definida por la formal separación de los poderes religioso y político" (p. 6). Por ejemplo, en el régimen de Santiago González, hubo una separación de la Iglesia y el Estado, en el periodo del 12 de abril de 1871 y el 1 de febrero de 1876. Araujo (2009) explica que "durante este breve lapso de tiempo se puede evidenciar la consolidación de la hegemonía absoluta del Estado sobre la 
sociedad, muy a pesar de la Iglesia" (p. 24). De acuerdo con ello, estos sacerdotes marcaron un precedente importante en la Iglesia, ya que desde ahí los religiosos iniciaron la participación en política. También cabe mencionar:

A finales del siglo XIX y principios de la década de 1950 el poder eclesiástico se caracterizó por el apoyo monolítico de las autoridades eclesiásticas al proyecto socioeconómico y político impulsado por la clase gobernante, civil y militar [...] para la Iglesia salvadoreña la apertura al nuevo orden se tradujo en cooperación con la clase dominante, que tenía sus fundamentos en la exportación cafetalera. La Iglesia constantemente fue ofrecida por sus jerarcas como institución útil al Estado [...] el mayor servicio de la Iglesia a la sociedad consistía en la formación de buenos ciudadanos al hacerlos buenos cristianos. El Estado, por su parte, necesitaba asegurar su estabilidad; la sola legitimación no era suficiente. La Iglesia prestó servicios apreciables en ambos aspectos. (Cardenal, 2001, pp. 895-896)

Definitivamente, la Iglesia ha sido y será pilar fundamental dentro de la sociedad, ya que tiene la responsabilidad de fomentar la armonía entre las personas que conviven en ella, además de ser la mediadora de conflictos que pueden suscitarse entre los diferentes sectores, con la finalidad de evitar la violencia.

\section{Evangelización de los indígenas y transformación de la religión en El Salvador}

La evangelización para los misioneros no fue fácil porque los indígenas estaban dispuestos a defender sus creencias, por esta razón emplearon métodos para realizar esta tarea. Al principio, fueron desordenados, ya que su principal objetivo era salvar las almas de los conquistados. Delgado (2011) explica que "los misioneros acompañaban al ejército conquistador para ir aplicando el sacramento del bautismo, para cumplir esta obligación de evangelización" (p. 97). Luego, identificaron diferentes recursos para enseñar a los indígenas el contenido de la doctrina católica: uno de ellos fue el canto con melodías sencillas como una forma efectiva de que ellos captaran el Evangelio y, a su vez, aprendieran español, según la posición de Holland (2011), quien afirma:

Los misioneros católicos empezaron la evangelización de Centro

América después de este suceso y la ocupación de la región, por los 
españoles en los años 1520. Aunque los amerindios en El Salvador tenían una religión bien desarrollada basada en la adoración de las fuerzas de la naturaleza. (p. 11)

En esta parte de la historia de El Salvador, la religión católica fue la que marcó la vida de las personas, pero con el pasar de los años se fue dando apertura a otras religiones, de modo que se tuvo que respetar la ideología y las creencias que fueron llegando al país, e implementar la libertad de religión. Al respecto, la Embajada de los Estados Unidos en el país presentó el Reporte de libertad de religión en El Salvador que hace énfasis en el respeto de religión y culto:

Se consagra la libertad de culto, al igual que otras leyes y políticas, y generalmente el gobierno acató dichas disposiciones en la práctica. La Constitución establece que todas las personas son iguales ante la ley y prohíbe la discriminación basada en nacionalidad, raza, género o religión. (párr. 7)

Este artículo se encuentra en la Constitución de la República de El Salvador de 1983 y la última modificación fue elaborada en 2014 en el capítulo 1 sobre derechos individuales, y su régimen de excepción específicamente en el artículo 3. De esta forma, "en el marco del Estado de derecho determina [sic] la Constitución de la República de El Salvador, el Gobierno garantiza el ejercicio pleno de la libertad de expresión y de culto por lo que siempre se guarda un respeto a la difusión del Evangelio cristiano" (Ministerio de Justicia, 2001, p. 176). Esto se demuestra en las diferentes actividades que los devotos manifiestan, en las misas que realizan los católicos o en los cultos que organizan los evangélicos, ya que son las dos religiones con un número mayor de adeptos. De igual forma, se respetan las creencias de las otras religiones que se profesan en el país, es decir, la Iglesia de Jesucristo de los Santos de los Últimos Días, Testigos de Jehová y la Comunidad de Cristo, y doctrinas no cristianas: bahaísmo, islam, budismo, judaísmo, grupos relacionados con el hinduismo, rosacrucismo, movimientos psíquico-espiritualistas de la nueva era y religión popular o sintética de tradiciones nativas. Lo anterior refuerza lo que se establece en el artículo 25, que explica: "Se garantiza el libre ejercicio de todas las religiones, sin más límite que el trazado por la moral y el orden público. Ningún acto religioso servirá para establecer el estado civil de las personas" (Constitución de la República de El Salvador de 1983). Como puede apreciarse, los salvadoreños ante la ley pueden ejercer la religión que llene sus creencias o convicciones, es decir, es un derecho fundamental que se refiere a la opción de cada ser humano de elegir libremente su religión, de no elegir ninguna 
(irreligión) o de no creer o validar la existencia de un Dios (ateísmo y agnosticismo), y ejercer dicha creencia públicamente, sin ser víctima de opresión, discriminación o intento de cambiarla a la fuerza. Por tanto, afirmar la libertad religiosa equivale a hacer un

juicio básico sobre la naturaleza del hombre y definir la esencia de la humanidad. Pero las implicaciones de la libertad de conciencia y de fe van mucho más allá de la cuestión filosófica acerca de la persona humana, ya que tienen una importancia crucial en la vida común, dentro de la sociedad. (Weigel, 1989, p. 50)

Desde este punto de vista, la religión ayuda a fortalecer los lazos de hermandad y a buscar establecer el bien común en la sociedad, ya que se persigue la paz entendida no solo como la ausencia de conflictos, sino también como la armonía positivamente cultivada entre personas.

\section{Relación entre el Estado y la Iglesia}

Con respecto a las relaciones del Estado y la Iglesia, es necesario explicar cuáles son los puntos clave en un correcto planteamiento de estos conceptos descritos, ya que se puede visualizar:

Entre el Estado Español y las confesiones religiosas existía una frontera y por tanto incidentes, la historia anota dos reacciones que no han sido desgraciadamente infrecuentes: para el Estado la tentación extrema ha sido desembarazarse de lo religioso; y para el poder religioso la tentación ha sido sofocar la necesaria e imprescindible autonomía del poder político. (Navarro-Valls, 2006, p. 27)

Esta situación da a comprender que ambas partes requieren autonomía para realizar sus actividades con la población. Para Möller (2008), la relación religión y Estado debe enfocarse en "mantener una orientación en los valores. Además, debe ayudar a fomentar procesos de involucramiento y desarrollo humano, siempre consciente de sus propias limitaciones" (p. 9). En este sentido, el Estado y la Iglesia tienen como objeto de su acción a los seres humanos, a quienes deben servir, por lo que el ordenamiento de cada una de estas dos entidades debe mantenerse en el ámbito de su propia vigencia: el Estado, en ofrecer bienestar a todos los ciudadanos, y la Iglesia, en su misión de brindar a todo ser humano una propuesta de salvación trascendente. 
Por otra parte, la Iglesia y Estado en El Salvador han estado de la mano. En 1881, hubo un cierto descontento de parte de la Iglesia frente a las medidas que se tomaron con respecto a la religión. Pero como el clero católico tenía buena relación con el presidente Francisco Dueñas, él llevó a cabo varias acciones para lograr incorporar a la Iglesia las actividades del Estado, entre ellas:

Reconstruyó con fondos del Estado la catedral arruinada después de la revolución de 1863; influyó poderosamente para que el concordato se llevara a efecto lo más fielmente posible; influyó mucho en la erección del cabildo eclesiástico de 1864; compró en 20,000 pesos una casa para residencia episcopal; pagó la subvención del poder eclesiástico, lo integra formalmente mejor que ningún otro gobierno; el 29 de julio de 1864 permitió el establecimiento de los capuchinos en Santa Tecla; igualmente permitió el ingreso de los jesuitas y de las hermanas de la caridad, apoyando económicamente ambas fundaciones; propuso a José Luis Cárcamo Rodríguez para obispo auxiliar, y, finalmente, dio libertad a las autoridades eclesiásticas para ejercer su ministerio en paz. (Araujo, 2009, p. 23)

A partir de lo anterior, se ve la participación política de la Iglesia, que alcanzó su crecimiento con el nombramiento de cinco clérigos como diputados constituyentes: el canónigo Aguilar por el distrito de San Salvador; el obispo electo Cárcamo por los distritos de Teotepeque y Aguas calientes; el canónigo Rodríguez por el distrito de Chalatenango; el sacerdote de Cacaguatique, Norberto Cruz, por los distritos de Jucuapa y Gotera; el sacerdote de San Francisco, Reyes Aparicio, suplente por el distrito de Teotepeque. La Constitución de 1871 fue finalmente aprobada, la cual avanzó en gran medida en la secularización de la educación y en la libertad de culto (Araujo, 2009). Los sacerdotes han tenido un papel protagónico en todos estos movimientos con el Estado, que en efecto sirvieron para mantener un equilibrio con la finalidad de beneficiar al pueblo.

La identificación Iglesia-Estado asumió las características propias de la Europa monárquica, en la que tal identificación era casi absoluta. Rivas (2010) explica que, al "producirse la independencia de la corona española, y construirse las nuevas entidades estatales, también la relación entre la Iglesia católica y el Estado fue modificada significativamente" (párr. 5). Por esta razón, la Iglesia salvadoreña estuvo entre los protagonistas de la formación del Estado nacional, al desempeñar un papel importante en el proceso de independencia y en la construcción del nuevo poder político. Por otra parte, en El Salvador se dio una apertura en la década de 1840: 
La Constitución salvadoreña de 1841, en su Art. 3, expone que en el Estado se profesa la religión católica, Apostólica y Romana, a quien el gobierno protegerá, pero se declara que todo hombre es libre para adorar a Dios según su conciencia, sin que ningún poder ni autoridad pueda, con leyes, órdenes y mandatos, de cualquier naturaleza que sean, perturbar o violentar las creencias privadas. (Avendaño, 2012, párr. 4)

Este artículo proporciona claridad en relación con las creencias de las personas $\mathrm{y}$, fundamentalmente, que a nadie se le puede obligar a profesar una religión. Así, queda establecido que la libertad de conciencia y la libertad religiosa constituyen el derecho humano más importante porque dentro de ella se instaura "la distinción radical que existe entre el individuo y el Estado, en el que se fundamenta cualquier esquema de derechos humanos" (García, 2008, p. 6). Ante esta afirmación, las personas tienen el derecho de profesar la religión que más les llene sus expectativas. Sin embargo, en 1864, en el artículo 5, solo se reconocía el culto católico, pero, en 1871, además de declararse un Estado católico, se dio apertura a otros cultos. Avendaño (2012) señala que "se tolera el culto público de las sectas cristianas en cuanto no ofendan la moral ni al orden público. Finalmente, en 1883, la nueva carta constitucional, en su Art. 14, declara el libre ejercicio de todas las religiones" (párr. 44). Este artículo actualmente se cumple en El Salvador, claro está, respetando las creencias de los demás. Por ejemplo, los cristianos evangélicos tienen la costumbre de realizar prédicas en parques, con la finalidad de evangelizar a las personas que frecuentan estos espacios públicos; y los católicos, en Semana Santa, realizan procesiones en las calles principales de la ciudad como recordatorio de la pasión, muerte y Resurrección de Jesucristo.

Por otra parte, en las década de 1970 y de 1980, las relaciones entre Iglesia y Estado se caracterizaron por una progresiva y fuerte erosión del espacio que el Estado reconocía al poder eclesiástico en la sociedad. De esta manera, el Vaticano retomó un discurso más centralista, por lo que reorganizó su política de penetración religiosa y cultural en la sociedad salvadoreña, solo cuando la Iglesia local resultó debilitada y limitada por la afirmación del Estado liberal, que se afianzó de dos maneras peculiares y complementarias:

- Creando la base legal e institucional de su poder mediante la afirmación progresiva de un pensamiento constitucional y legislativo fuerte y secularizador.

- Cimentando un nuevo tipo de fidelidad hacia aquel basado en una "religión cívica" que se propone reemplazar los vínculos tradicionales 
(relacionados con la religión, la etnia o la familia) por una lealtad hacia el Estado. (Russo, 2007, p. 278)

En la historia de la Iglesia de El Salvador, se registra la influencia de la teología de la liberación que en América Latina empieza a cobrar fuerza desde la Conferencia Episcopal de Medellín en 1968. El objetivo de esta fue "inducir a muchos cristianos latinoamericanos a un discernimiento crítico de las condiciones sociohistóricas de los pueblos del continente a la luz de la palabra de Dios" (González, 2006, p. 564), que se materializó en las comunidades eclesiales de base (CEB) cuyos representantes fueron Rutilio Grande y monseñor Oscar Arnulfo Romero, quienes trabajaron para concientizar a la población de la búsqueda de un cambio social. Las CEB históricamente participaron en "las grandes luchas sociales del pueblo salvadoreño: por una reforma agraria, condiciones justas para los trabajadores, y los derechos a educación, salud y viviendas dignas" (Marshall, 2015, p. 10). Actualmente, las CEB siguen en la lucha de lo inconstitucional, en contra de la minería metálica y otras situaciones injustas que suceden en la sociedad.

Debido a la guerra civil que vivió el país entre 1970 y 1992, el rol de la Iglesia, independientemente de la doctrina religiosa que profesaran, fue de servir como un refugio a los creyentes. A manera de ejemplo, hay que mencionar el trabajo del Comité de Madres y Desaparecidos Políticos de El Salvador Monseñor Romero (Comadres), institución que fue fundada para ayudar a las víctimas y las familias de las personas desaparecidas y los asesinatos durante la guerra civil en El Salvador. Comadres sigue trabajando por esa causa y por otros asuntos de derechos humanos. Otro ejemplo es la Oficina de Tutela Legal del Arzobispado de El Salvador, instancia eclesial dependiente de la Vicaría Episcopal de Promoción Humana, Cáritas de la Arquidiócesis de San Salvador, que promueve procesos jurídicos, formativos y de memoria histórica, con la finalidad de contribuir al cumplimiento de los derechos humanos de los salvadoreños, especialmente de los sectores más vulnerables.

\section{La religión en El Salvador en la actualidad}

Para avanzar en la línea de tiempo en la transformación de la religión en El Salvador, en el siglo XX la realidad salvadoreña, específicamente en 1986, era: “Un porcentaje de salvadoreños católicos oscilaba entre un $65 \%$ y un $70 \%$; de un $12 \%$ a un $15 \%$ que se conocían como evangélicos y el resto manifestaban su adscripción a otros credos o bien un cierto agnosticismo" (De la Corte, 2001, p. 35). Como lo reflejan estos datos, siempre hay más católicos que evangélicos y de otras religiones 
en el país; sin embargo, hay que mencionar además el contexto religioso actual, porque existe una serie de encuestas de opinión pública realizadas entre 1988 y 2008 en las que se incluye información acerca de la "afiliación religiosa" en El Salvador, que presenta un panorama más claro de lo que ha ocurrido en el país. Entre 1988 y 1995, dos estudios revelaron que no se habían dado cambios significativos en cuanto a la afiliación religiosa desde mediados de la década de 1980. El primero fue conducido en 1988 por investigadores en la Universidad Centroamericana José Simeón Cañas de San Salvador, que revelaba que el 67.1 \% eran católicos, el $16.4 \%$ protestantes, el 4.8 \% tenían otra religión y el 14.7 \% no reportaban religión o no respondían. El segundo fue realizado en 1995 por CID Gallup, que mostraba que el $67.8 \%$ eran católicos, el 16.8 \% eran protestantes, el $2.3 \%$ tenían otra religión y el 13 \% no tenían religión o no respondían; sin embargo, entre 1995 y 2004, las encuestas nuevas mostraban un aumento considerable de la población protestante, del $16.8 \%$ pasó al $25.0 \%$, con un descenso en la afiliación a la Iglesia católica romana: del $67.9 \%$ en 1995 al 56,5\% en 2004, una baja del $11.4 \%$. Todos estos estudios tienen un margen de error de más o menos el $2.5 \%$ (Universidad Centroamericana José Simeón Cañas, 2009). Estos porcentajes reflejan que las personas pueden cambiar sus convicciones de la iglesia a la que han frecuentado con regularidad, pero lo importante es que siguen creyendo en Dios como ser todopoderoso.

El mismo estudio de la Universidad Centroamericana José Simeón Cañas muestra: "La mitad de la población 50.4 \% sigue profesando la religión católica; el $38.2 \%$ se declara cristiano evangélico; el $8.9 \%$ dice no tener religión y el restante $2.5 \%$ pertenece a otras denominaciones religiosas". Sin embargo, estos porcentajes han tenido un gran cambio en 2015. La U.S. Department of State, con el apoyo de esta misma universidad, desarrolló una encuesta sobre la preferencia de religión, que arrojó los siguientes datos:

La población total asciende a 6.1 millones (cifra a julio de 2015), aproximadamente el $47 \%$ de la población se identifica como católica, el $34 \%$ como protestante, el 16.2 \% "sin religión" y el 2.8 \% “otra religión". Entre los grupos que juntos totalizan menos del $3 \%$ de la población se encuentran los Testigos de Jehová, devotos de Krishna (Sociedad Internacional para la Conciencia de Krishna), musulmanes, judíos, budistas y mormones. Un segmento pequeño de la población se adhiere a creencias religiosas indígenas, con cierta mezcla de estas creencias con las de otras religiones como el catolicismo. (p. 3)

Como se puede analizar en estas cifras, la religión católica sigue dominando en nuestro país, aunque ha perdido varios adeptos en el transcurso de estos años, 
aumentando, por otro lado, los que prefieren las prácticas evangélicas y otro porcentaje que pertenece a pequeñas congregaciones. Un dato importante que vale la pena mencionar es que las religiones católica y evangélica para mantener su legado han creado instituciones educativas a fin de formar a los estudiantes con bases religiosas, aspecto que se desarrolla en el siguiente apartado.

\section{Relación de la religión y la educación salvadoreña}

En relación con la religión y la educación, las instituciones educativas, aunque sean públicas o privadas, deben cumplir con los lineamientos establecidos por el Ministerio de Educación de El Salvador. Por tanto, está establecido que "la educación pública es laica. En el país funcionan escuelas religiosas privadas. Todas las escuelas privadas, religiosas o laicas deben cumplir las mismas normas para ser aprobadas por el Ministerio de Educación" (Embajada de Estados Unidos, 2002, párr. 14). Asimismo, en los fines de la educación, se establece en el capítulo II, artículo 2, que se debe "lograr el desarrollo integral de la personalidad en su dimensión espiritual, moral y social" (Decreto 917/1996, de 12 de diciembre). En este sentido, no está permitido impartir un tipo de religión en las escuelas públicas, sino más bien buscar formar personas íntegras para la sociedad. Sin embargo, en las escuelas privadas, sí tienen la libertad de impartir la doctrina religiosa bajo las que tienen sus directrices, católicas, evangélicas u otras creencias.

De acuerdo con lo anterior, la existencia de la educación religiosa escolar es una actividad que se desarrolla en la libertad de religión que el Estado permite a la Iglesia. Por tanto, hay una tendencia creciente a justificar la enseñanza religiosa como exigencia de los derechos de la persona, de la libertad religiosa y de cultos. En el país, en el sistema educativo, se tiene como objetivo formar ciudadanos integrales. En las leyes salvadoreñas, se encuentra establecido: “La Educación Religiosa Escolar, [...] se da en el ámbito de la formación pública y privada. Este servicio educativo ha sido reconocido legalmente a través de diversos instrumentos jurídicos como la constitución, las leyes, decretos y otros" (Duarte, 2013, p. 55). En este sentido, el Ministerio de Educación tiene como uno de sus objetivos fundamentales profundizar en la educación en valores. Por esta razón, en la reciente reforma educativa del periodo de 1995 a 2005, se pretendió que la educación desarrollara "un sistema general de valores positivos para cada persona como individuo, para las organizaciones sociales básicas como son la familia y la comunidad, para la nación y el país" (Ministerio de Educación, 2000, p. 66). La relación entre libertad religiosa y educación en El Salvador establece el 
hecho del comportamiento religioso de la sociedad como elemento constitutivo de la vida cotidiana de las sociedades, lo que ha posibilitado tanto la formación religiosa como la educativa de los adeptos o militantes de una religión, que ha tenido como resultado ciudadanos integrales de la comunidad. Este punto lleva a la formación de un Estado laico que está conformado por ciudadanos, interesados por tratar a todos por igual, tanto a los creyentes de cualquier religión como a los no creyentes. En tal sentido, evita la discriminación por cuestiones religiosas, pero tampoco favorece alguna confesión determinada, aspecto que se explica en el siguiente apartado.

\section{El laicismo y la educación en El Salvador}

En la Constitución de la República de El Salvador, en su reforma de 1883, en el artículo 30, se menciona: “La Nación garantiza la existencia y la difusión de la enseñanza primaria, la cual será gratuita, laica y obligatoria; lo mismo que el fomento de los establecimientos públicos de ciencias, artes y beneficencia" (párr. 2). En las escuelas públicas salvadoreñas, no solo a nivel primario, sino a nivel básico y medio no está permitido que los docentes enseñen una religión específica a los estudiantes, pero sí se fomenta el respeto a Dios, ya que ese aspecto puede garantizar que, aunque tengan dificultades serias en la vida, no sucumbirán ante ellas, porque tendrán las herramientas necesarias para afrontar con éxito la adversidad, algo que los docentes pueden inculcar en los estudiantes.

Con respecto a un Estado laico, debe "garantizar que todas las manifestaciones espirituales sean estas artísticas, religiosas, científicas, filosóficas u otras expresiones sociales que se lleven a cabo no lesionen las libertades comunes de toda la población" (Montalvo, 2013, párr. 12). Esto implica que el Estado debe legislar democrática e independientemente de las creencias religiosas de la ciudadanía. Históricamente, la educación laica inició en el siglo XIX con Argentina, Uruguay, Colombia, México y El Salvador. González (2014) expresa: "La escuela pública del siglo XIX fue creada para proporcionar las competencias básicas al futuro ciudadano de la nación. El principio fue asumido por las repúblicas latinoamericanas que surgieron en el contexto de las luchas independentistas" (párr. 2). Mucho se ha escrito y especulado sobre la influencia de la Revolución francesa en la Revolución de independencia de América Latina. La historiografía liberal latinoamericana se ha empeñado particularmente en destacar esa influencia, y la ha relevado hasta el punto de mostrar a nuestro proceso emancipador como un efecto histórico de la gran transformación francesa. Sin embargo, un análisis 
objetivo de aquellos fenómenos muestra que esa influencia no fue tan decisiva, y que la independencia de nuestros países fue sustancialmente el resultado de una larga crisis colonial y de una creciente toma de conciencia de los pueblos latinoamericanos respecto de su destino histórico.

En este sentido, el laicismo llegó a El Salvador a finales del siglo XIX y "produjo una ruptura silenciosa entre el tradicional convenio Iglesia-Estado, que poco a poco se fue acrecentando y terminó con el destierro del obispo de San Salvador y su curia por sus discrepancias con el proceso de laicización" (Villalona, 2014, párr. 12). La separación del Estado de la Iglesia es intrínseca por el respeto de la autonomía de ambas instituciones, es decir, que la Iglesia se gobierna según dogmas teológicos de fe y el Estado se gobierna según leyes que provienen de la soberanía del pueblo.

Para profundizar más en el término laicismo, Rodríguez (2012) lo define como "la independencia del individuo o del Estado con respecto a cualquier organización o confesión religiosa" (párr. 4). De acuerdo con el autor, el laicismo es un movimiento ilustrado que defiende la autonomía de cada persona e impulsa su derecho a ser educada libremente sin adoctrinamiento dogmático. No se trata de una nueva religión laica, ni mucho menos, ni es en sí mismo una cultura, sino la convivencia de todas las posibles culturas. Otra definición de laicismo es la de Reyes (s. f.), quien lo define como "la separación entre el Estado y la Iglesia o confesión religiosa" (párr. 1), por tanto, el Estado salvadoreño es laico. Martínez (2010) afirma que el país es "como un Estado soberano que es República Democrática, en donde su soberanía deriva del pueblo que es múltiple y diverso en sus concepciones y creencias" (p. 9). Esto afirma que la riqueza de los países es la diversidad que se debe valorar, puesto que engrandece al país. En este sentido, se tiene la convicción de que lo religioso, como otras dimensiones del ser humano, es educable, de tal manera que enriquece la forma en que se entiende a sí mismo. "La clase de religión ofrece un aporte particular y original a la educación religiosa, la parte del carácter académico y sistemático que difícilmente ofrecen las mediaciones escolares" (Méndez y Lazo, 2009, p. 51). En este sentido, la educación religiosa trasciende lo estrictamente académico y llega hasta el punto de la formación integral del ser humano, elemento que fortalece en los estudiantes el amor a Dios y hacia las personas. 


\section{Conclusión}

Desde que aconteció la conquista en El Salvador, se han dado cambios en materia de religión, como ejemplo el rey de España se comprometió ante el papa a evangelizar a los indígenas de las tierras descubiertas y conquistadas por ellos, de modo que fueron los primeros destinatarios de la obra evangelizadora de misioneros, frailes y clérigos venidos a estas tierras. En la medida en que la evangelización fue avanzando, fue creciendo el celo de los evangelizadores y así desplegaron con más fuerza su poder espiritual y humanitario.

Por otra parte, con la migración de otras personas al continente y con diferentes ideologías religiosas, fueron introduciendo sus creencias, de tal manera que fue desarrollándose la libertad de culto, que se constituyó en un derecho de las personas, base principal de cualquier sistema, ya que no amenaza a ningún Estado que esté sirviendo con legitimidad al bien común de su pueblo; esta libertad se instituye dentro de la misma estructura del ser humano, porque es la fuente de obligaciones morales y religiosas, y también porque no encuentra descanso sin la posibilidad de encontrar a Dios como un refugio ante las vicisitudes de la vida.

En El Salvador, desde su origen, la Iglesia católica fue importante en el desarrollo de la educación al realizar los primeros intentos por alfabetizar a la población, por el poder que tenía la misma Iglesia sobre la población y por la insistencia de los españoles por imponer sus creencias sobre los indígenas.

La Iglesia católica ha sido desde siempre un poder que, ya desde los entretelones de los diferentes gobiernos o desde "la oposición", ha influido en las estrategias políticas y sociales del Estado salvadoreño, que se ha fundido en ciertos periodos de nuestra historia con el Estado mismo y ha dictado lineamientos para su gestión.

La historia constitucional de El Salvador ha sido ambivalente en lo referente a la relación entre el Estado-Iglesia, pero es pertinente resaltar que desde 1883 hasta la fecha las constituciones han respetado la libertad religiosa. Lo establecido en el desarrollo de la investigación permite concluir que el Gobierno de un Estado soberano debe respetar el ejercicio del poder absoluto que el pueblo le deposita, y no debe ni puede compartirlo con otras instituciones, sean estas religiosas o no.

Hay que mencionar, además, que la Constitución Política contiene los principios laicos que caracterizan a los Estados modernos. Así, las autoridades están obligadas a no adherirse públicamente a ninguna religión y a asegurar que las creencias religiosas no influyan en la política nacional. 
Por otra parte, queda claro que en el sistema educativo nacional, específicamente en lo público, no se puede enseñar una religión porque viola lo establecido en la Constitución de la República y las leyes de educación; sin embargo, se procura enseñar a los estudiantes valores morales y cívicos. A las instituciones públicas que son católicas, por el contrario, se les respeta esa dimensión formativa para sus estudiantes; y los colegios privados, que en su mayoría son fundados con identidad religiosa católica o evangélica, tienen la libertad de enseñar su doctrina a los estudiantes que reciben educación; esto se da en los niveles de parvularia, básica y educación media (bachillerato), para ser más específicos.

Finalmente, al vivir en una sociedad plural desde el punto de vista de las creencias religiosas, el Estado tiene la obligación de velar por los derechos de todos los ciudadanos sin ningún tipo de discriminación, y para ello tiene que configurarse como un Estado laico e independiente.

\section{Referencias}

Aguilar Aviles, G. (1995). Reforma educativa en marcha. Documento I: un vistazo al pasado de la educación en El Salvador. San Salvador, El Salvador: Ministerio de Educación. Recuperado de https:/es.slideshare.net/adalbertomartinez/ un-vistazo-al-pasado-reforma-educativa-en-marcha-i

Araujo Lozano, J. G. (2009). La Iglesia católica salvadoreña y la laicización de la educación en 1881: ¿un proyecto liberal frente a una respuesta ultramontana? (Tesis de maestría, Universidad Centroamericana José Simeón Cañas, Antiguo Cuscatlán, El Salvador). Recuperado de http://www.uca.edu.sv/filosofia/admin/files/1257454476. pdf

Avendaño Rojas, X. (2012). La protección estatal a la Iglesia católica en Centroamérica: entre el patronato y el concordato. Boletín de la Asociación para el Fomento de los Estudios Históricos en Centroamérica, 52. Recuperado de http://www.red-redial. net/pt/referencia-bibliografica-65787.html

Cardenal, R. (2001). El poder eclesiástico en El Salvador, 1871-1931 (2. ed.). San Salvador, El Salvador: Consejo Nacional para la Cultura y el Arte.

Constitución de la República de El Salvador (1983). Recuperado de http://www.oas. org/dil/esp/constitucion_de_la_republica_del_salvador_1983.pdf

Corte Ibáñez, L. de la (2001). Religión y política desde un punto de vista psicosocial: reflexiones a partir de la obra de Ignacio Martín-Baró. Revista de Ciencias de las Religiones, 6, 33-46. Recuperado de https:/www.researchgate.net/profile/Luis_ De_la_Corte/publication/27572835_Religion_y_politica_desde_un_punto_de_ vista_psicosocial_Reflexiones_a_partir_de_la_obra_de_Ignacio_Martin-Baro/ links/00463532dfddcbd858000000.pdf 
Decreto 917/1996, de 12 de diciembre, ley general de educación.

Delgado Acevedo, J. (2011). Historia de la Iglesia en El Salvador. Vol. I: Los inicios de la evangelización en tierras salvadoreñas y la paulatina organización de la misma hasta la independencia de El Salvador. San Salvador, El Salvador: Secretaría de Cultura de la Presidencia.

Duarte Cavaría, H. (2013). La libertad religiosa como derecho, concepto y contenido (Tesis de maestría). Universidad Nacional de Educación a Distancia, Madrid, España. Recuperado de http://repositorio.uned.ac.cr/reuned/bitstream/120809/1141/1/Libertadculto.pdf

Embajada de Estados Unidos (2002). Reporte de libertad de religión en El Salvador. Recuperado de http://bdigualdad.lim.ilo.org/index.php/component/content/ article/36-informes/456-estudios-generales-de-el-salvador.html

García Martínez, A. (2008). La influencia de la cultura y las identidades en las relaciones interculturales. Kairos: Revista de temas sociales, 22. Recuperado de https:// dialnet.unirioja.es/servlet/articulo?codigo $=2777529$

Gispert, C. (coord.) (2006). El mundo precolombino. Madrid, España: Océano.

González Torres, J. (2006). Cristianismo y liberación en El Salvador: el boletín católico Justicia y Paz, 1972-1980. Realidad: Revista de Ciencias Sociales y Humanidades, 110, 563-584. Recuperado de https://doi.org/10.5377/realidad.v0i110.3431

González Torres, J. (2012). Del "ciudadano católico" al "ciudadano laico". La escuela pública primaria y la formación de los futuros ciudadanos: El Salvador 1824-1890 (Tesis doctoral). Universidad Centroamericana José Simeón Cañas, San Salvador, El Salvador. Recuperado de http://www.uca.edu.sv/filosofia/admin/files/1341957152.pdf

González Torres, J. (19 de octubre de 2014). La escuela sin Dios o cómo la escuela salvadoreña se hizo laica. Recuperado de http://www.elfaro.net/es/201410/academico/16102/La-escuela-sin-Dios-o-c \%C3 \%B3mo-la-escuela-salvadore \%C3 \%B1a-se-hizo-laica.htm

Holland, C. L. (2011, marzo 12). Enciclopedia de religión en las Américas y la península ibérica: El Salvador. San Pedro, Costa Rica: Programa Latinoamericano de Estudios Sociorreligiosos. Recuperado de http://www.prolades.com/historiografia/3-ElSalvador/rel_els09spn.pdf

Lorenzana Olivares, J. A., Mena de Castro, X. M., Regalado Orellana, J. C. y Rodríguez, P. E. (2011). Influencia del ambiente escolar en la formación de la disciplina, y su efecto en el rendimiento académico de los alumnos de II ciclo de educación básica de centros escolares públicos laicos y semiautónomos administrados por la Iglesia católica de la ciudad de Santa Ana durante el tercer trimestre del año lectivo 2010 (Tesis de grado).Universidad de El Salvador, San Salvador, El Salvador. Recuperado de http://ri.ues.edu. sv/id/eprint/894/

Marshall, L. A. (2015). Un gesto vale más que mil palabras: las comunidades eclesiales de base de El Salvador en la construcción de celebraciones eucarísticas y bautismales (Tesis de maestría). Universidad Centroamérica José Simeón Cañas, San Salvador, El 
Salvador. Recuperado de https://studylib.es/doc/8215645/un-gesto-vale-m \%C3 \%A1s-que-mil-palabras--las-comunidades-ecles...

Martínez Castro, F. (2010). Garantías de la legislación salvadoreña que inciden en el carácter laico del Estado. San Salvador, El Salvador: Movimiento por una Cultura Laica. Recuperado de https://laicismo.org/data /docs/archivo_1221.pdf

Méndez, M. y Lazo, M. (2009). Para que todos tengan vida: una propuesta de la Universidad Don Bosco para la educación religiosa escolar en Centroamérica. Diálogos. Recuperado de http://www.udb.edu.sv/dialogos/PDF/dialog1experiencia. pdf

Ministerio de Educación (2000). Fundamentos curriculares de la educación nacional. San Salvador, El Salvador: Autor. Recuperado de https://webquery.ujmd.edu.sv/ siab/bvirtual/BIBLIOTECA \%20VIRTUAL/LIBROS/F/ADMF0000411.pdf

Ministerio de Educación (2010). Módulo 1: segundo año de bachillerato. San Salvador, El Salvador: Autor. Recuperado de https://bvinsl.files.wordpress.com/2013/08/ leng-11u1.pdf

Ministerio de Justicia (2001). Foro Iberoamericano sobre Libertad Religiosa. Madrid, España: Autor.

Möller, A. (2008). Religión, desarrollo y cooperación: un ensayo teórico y metodológico. Teoría y Praxis, 13, 5-24. Recuperado de http://redicces.org.sv/jspui/ handle/10972/916

Montalvo, W. (6 de octubre de 2013). El carácter laico del Estado: una reflexión desde El Salvador. Recuperado de https://laicismo.org/el-caracter-laico-del-estado-unareflexion-desde-el-salvador/

Navarro-Valls, R. (2006). Para evitar equívocos: laicidad y laicismo. Nueva Revista de Politica, Cultura y Arte, 103, 23-28.

Reyes Vizcaíno, P. M. (s. f.). ¿Qué es el laicismo? Recuperado de https://es.catholic.net/ op/articulos/23492/cat/1199/que-es-el-laicismo.html\#modal

Rivas, C. (25 de agosto de 2010). El mito del Estado Laico (1). Recuperado de https:// laicismo.org/el-mito-del-estado-laico-i/

Rodríguez, F. (20 de febrero de 2012). El principio de separación entre Iglesia y Estado. Recuperado de https://laicismo.org/el-principio-de-separacion-entre-iglesia-y-estado/

Russo, M. (2007). Relaciones entre Estado e Iglesia católica en El Salvador (finales del siglo XIX, comienzos del XX). Cuicuilco, 14(41), 273-289. Recuperado de https:// www.redalyc.org/pdf/351/35112370011.pdf

Universidad Centroamericana José Simeón Cañas (2009). La religión para las y los salvadoreños. Boletín de Prensa, 24(4). Recuperado de http://www.uca.edu.sv/publica/iudop/Web/2009/boletinrel_2009.pdf

U.S. Department of State (2015). International Religious Freedom Report for 2015. Recuperado de https://2009-2017.state.gov/j/drl/rls/irf/religiousfreedom/index.htm 
Villalona, C. (20 de septiembre de 2014). Escuela sin Dios: la refundación del Estado salvadoreño. Transparencia Activa. Recuperado de http://www.transparenciaactiva.gob.sv/escuela-sin-dios-la-refundacion-del-estado-salvadoreno

Weigel, G. (1989). Fieles y libres: catolicismo, derechos humanos y democracia. Libro Libre. 